\title{
A Enciclopédia Ashgate de Monstros Literários e Cinematográficos
}

Lúcio Reis Filho ${ }^{1}$

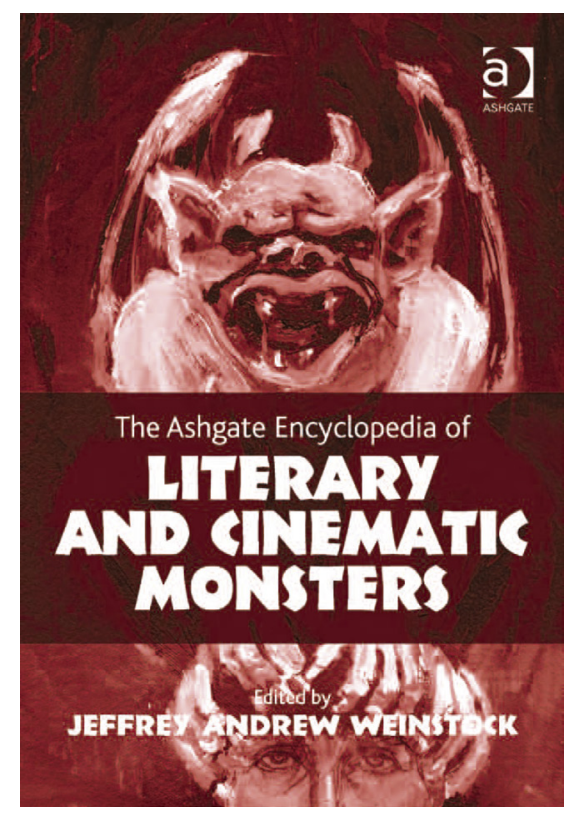

\section{Resenha}

WEINSTOCK, Jeffrey Andrew. The Ashgate Encyclopedia of literary and cinematic monsters. Dorchester: Ashgate Publishing, 2014.

${ }^{1}$ Professor da Universidade do Estado de Minas Gerais - Unidade Campanha e Doutorando em Comunicação pela Universidade Anhembi Morumbi. Autor de artigos em livros e revistas científicas. Co-autor do capítulo "La invasión zombi en el cine de terror independiente latinoamericano", publicado no livro Horrofílmico: Aproximaciones al cine de terror en Latinoamérica y el Caribe (Editorial Isla Negra, 2012). 
Revista Brasileira

de Estudos de

Cinema

e Audiovisual

Os monstros, em suas múltiplas formas, despertam o fascínio na imaginação humana desde a aurora dos tempos históricos. A palavra latina monstrum relaciona-se ao verbo monstrare (mostrar/revelar), que parece trazer consigo um presságio. Algo ameaçador espreita, no universo que habitamos. As artes, a literatura e as mídias audiovisuais atestam que os monstros estão profundamente enraizados nas culturas humanas. São quebra-cabeças ontológicos que demandam solução. Nesse sentido, têm sido interpretados como abortos da natureza, sintomas de angústias profundas ou personificação de medos humanos, tabus e do próprio zeitgeist. São coisas que não deveriam existir, mas que de certa forma existem por terem sido incorporadas ao imaginário, e trazem à tona questões incômodas sobre a nossa própria existência. "Da mesma forma como o Sr. Hyde é o reflexo obscuro do Dr. Jekyll, os monstros em geral são o reflexo de nós mesmos, repelentes e fascinantes em igual medida" (WEINSTOCK, 2014, p. 3).

Fonte para pesquisadores e estudantes, a The Ashgate Encyclopedia of literary and cinematic monsters consiste em uma coletânea de textos científicos sobre o monstro e a monstruosidade na cultura popular, com destaque para os campos da literatura, do cinema e do audiovisual. Segundo Jeffrey Andrew Weinstock, ${ }^{2}$ a obra é um conjunto de partes agrupadas, uma espécie de monstro de Frankenstein (2014, p. 5). Isso porque a Enciclopédia conta com mais de 200 entradas, escritas por especialistas da área. Autor de vasta bibliografia sobre o horror, Weinstock foi o nome selecionado pela britânica Ashgate Publishing para encabeçar o projeto, que tomou forma após a triagem de um catálogo inicial com mais de 1000 possíveis entradas. A listagem definitiva, organizada em ordem alfabética, foi em grande parte sugerida pelos participantes da lista de discussão da International Association for the Fantastic in the Arts (IAFA). O editor e os colaboradores da Enciclopédia, então, decidiram quais monstros mereciam seu próprio verbete e quais viriam a compor uma das categorias mais amplas e genéricas.

${ }^{2}$ Professor de Inglês e Coordenador do Departamento de Graduação da Central Michigan University, Estados Unidos. Autor de vasta bibliografia sobre monstros e monstruosidade. Dentre seus livros publicados figuram The vampire film: Undead cinema e três volumes sobre a obra de ficção de H.P. Lovecraft. 
Revista Brasileira

de Estudos de

Cinema

e Audiovisual

Importante frisar que os conceitos de monstro e monstruosidade, dentro da perspectiva teórica escolhida pelo editor, englobam os seres que, de certa maneira, violam as leis da natureza como a conhecemos. As justificativas para essa abordagem aparecem na introdução, e podem ser explicadas pelo referencial teórico que cimenta as bases dessa proposta da Ashgate. Destaco o trabalho de dois autores citados: a reflexão apresentada pela antropóloga Mary Douglas em Pureza e perigo: ensaio sobre as noções de poluição e tabu (1966) e a ideia de impureza enquanto relação entre ordem e desordem, ser e não-ser, vida e morte têm sido aplicadas ao exame dos monstros, que passam a ser entendidos como violações categóricas. Consoante a essa ideia, o filósofo Noël Carroll, em Filosofia do horror ou paradoxos do coração (1990), define o monstro como uma perturbação que ameaça a ordem natural e afeta os demais personagens da narrativa, bem como o espectador, cujas respostas emocionais vão de encontro àquelas dos personagens, repletas de medo e repulsa. Nesse sentido, vampiros, fantasmas, zumbis e outras criaturas "não-mortas" contrariam a distinção entre vida e morte. Em outras palavras, desconstroem nosso entendimento sobre como as coisas são e violam as noções de como elas deveriam ser.

Compêndios sobre monstros têm sido regularmente publicados, sendo comuns desde os bestiários medievais. No entanto, pode-se diferenciar a Enciclopédia da Ashgate dos trabalhos que a antecedem. Se em obras como a Encyclopedia of things that never were (1985), de Michael Page e Robert Ingpen, o interesse recai sobre o folclore, no trabalho em questão o enfoque é dado à literatura e ao audiovisual. As raízes folk e os antecedentes históricos são inevitavelmente apresentados, em geral no primeiro tópico do verbete, com o objetivo de introduzir o leitor. Os tópicos seguintes variam de acordo com o objeto e com os meios de sua reinserção na cultura popular, que pode ocorrer, ao longo do tempo, na literatura, no cinema, na televisão, nos games, nos quadrinhos, etc. Por exemplo, "Drácula" (p. 177-83) e o "Monstro de Frankestein" (p. 238-43) aparecem na literatura, no cinema e em diversas outras mídias. Ambos foram submetidos a significativas transformações culturais, tendo sido amplamente ressignificados pelo imaginário cinematográfico - diferentemente de "Nosferatu" (438-39), que, embora tenha suas origens no romance Drácula (1897), de Bram 
Revista Brasileira

de Estudos de

Cinema

e Audiovisual

Stoker, aparece como um verbete mais específico por se tratar de uma contribuição formal ao mythos do vampiro, legada pelo cinema a partir do filme Nosferatu (Nosferatu, eine Symphonie des Grauens, dir. F.W. Murnau, 1922).

A Enciclopédia Ashgate não inclui apenas monstros de existência ubíqua, como os vampiros, dragões, lobisomens e zumbis, ou os espécimes da fauna extraordinária do mundo clássico e da Idade Média. De acordo com critérios de relevância definidos, os especialistas também selecionaram criaturas menos conhecidas da mitologia mundial e exemplares representativos do horror contemporâneo. Destes, alguns pertencem estritamente ao imaginário cinematográfico, ou à literatura a ele relacionada, como a "Bruxa de Blair"3 ( $p$. 52-54), "Blob"4 (p. 54-55), "Pinhead" (p. 466-67) e "Cenobitas"5 (p. 74-75), "Chucky, o brinquedo assassino"6 (p. 94-95), "O Monstro da Lagoa Negra"7 (p. 102-104), "Godzilla"8 (p. 291-94), "King Kong"9 (p. 356-57), "Freddy Krueger"10 (p. 366-67) e "Jason Voorhees"11 (p. 573-74). Reforçamos que outros

\footnotetext{
${ }^{3}$ Objeto do filme de horror de mesmo nome (dir. Daniel Myrick; Eduardo Sánchez, 1999). Segundo as lendas contadas no filme e no material de divulgação, a bruxa de Blair seria o espectro de uma mulher acusada de bruxaria em 1785, abandonada à morte pelos habitantes do povoado de Blair.

${ }^{4}$ Forma de vida alienígena gelatinosa que chega à Terra em um meteoro e invade uma pequena cidade no filme de horror e ficção científica A bolha assassina (The blob, dir. Irvin S. Yeaworth Jr., 1958).

${ }^{5}$ Os cenobitas são os demônios da obra The hellbound heart (1986), de Clive Barker, e da sua adaptação para o cinema, Hellraiser (dir. Clive Barker, 1987). O mais famoso recebe o nome de "Pinhead" (Doug Bradley), devido à sua aparência: cabeça pálida como a de um cadáver, sem pelos e escarificada por dezenas de pregos.

${ }^{6}$ Antagonista da série iniciada com Brinquedo assassino (Child's play, dir. Tom Holland, 1988), Chucky é um boneco homicida que lembra um homem de retalhos ou um monstro de Frankenstein em miniatura.

${ }^{7}$ Humanoide anfíbio que aparece em três filmes da Universal da década de 50: O Monstro da Lagoa Negra (Creature from the Black Lagoon, dir. Jack Arnold, 1954), A revanche do Monstro (Revenge of the Creature, dir. Jack Arnold, 1955) e À caça do Monstro (The Creature walks among us, dir. John Sherwood, 1956).

${ }^{8}$ Fera gigante, bípede e anfíbia, semelhante a um dinossauro, que estreou no cinema japonês de ficção científica na produção que leva o seu nome (dir. Ishiro Honda, 1954).

${ }^{9}$ Gorila gigante do filme de mesmo nome (dir. Merian C. Cooper e Ernest B. Schoedsack, 1933).

${ }^{10}$ Criado por Wes Craven, Freddy Krueger é um ser que habita o mundo dos sonhos, no qual é capaz de assassinar fisicamente crianças enquanto dormem. Antagonista da franquia A hora do pesadelo, aparece pela primeira vez no filme de 1984. Usa chapéus e roupas velhas, tem a pele queimada e desfigurada e mata com uma luva com garras metálicas cortantes.

${ }^{11}$ Assassino em massa da franquia Sexta-feira 13 (1980-2009). Conhecido pela icônica máscara de hóquei e por perseguir e matar adolescentes na região de Crystal Lake.
} 
Revista Brasileira

de Estudos de

Cinema

e Audiovisual

exemplares foram agrupados em categorias temáticas, tais como "Monstros nas Mil e uma Noites" (p. 23-26), "Monstros na Bíblia" (p. 40-44), "Monstros em Dungeons and Dragons" (p. 192-95) e "Monstros nos Videogames" ( $p$. 565-68), ou pelo sobrenome de autores que acabaram por criar o seu próprio bestiário, como Dante, Lovecraft, Tolkien, entre outros.

Embora uma definição de monstro como a que foi adotada pela Enciclopédia Ashgate - todo ser que, de certa forma, viola as leis da natureza - muitas vezes exclua dessa categoria os seres humanos, a despeito do mal que possam ter causado, alguns homens e mulheres, históricos e ficcionais, não foram esquecidos. É o caso da "Condessa Bathory"12 (p. 32-34), incluída não devido aos crimes que cometeu, ou por estes terem sido considerados monstruosos, mas pelo fato de sua própria figura ter sido moldada por tradições literárias e cinematográficas que a relacionaram ao imaginário dos vampiros. O mesmo ocorre com "Jack, o estripador" (p. 349-352), no que se refere ao imaginário dos assassinos em série, incluídos na categoria "Psicopatas". Sem contar personagens da literatura ou do cinema, herdeiros dessas tradições, que também ganharam seus próprios verbetes, como é o caso dos vampiros "Carmilla"13 (p. 72-74) e "Lestat de Lioncourt"14 (p. 375-77), e dos assassinos "Hannibal Lecter"15 (p. 370-372) e "Norman Bates"16 (p. 31-32).

Ainda que limitada pelo espaço e pelas escolhas do editor, a Enciclopédia Ashgate pretende ser mais do que um exaustivo bestiário. É a sementeira de um imaginário recorrente do ponto de vista histórico, cuja fertilidade torna-se evidente pelas formas com que os humanos vêm povoando este mundo (e outros) de seres estranhos e fascinantes que espelham nossos desejos e an-

\footnotetext{
12 Também conhecida como "Condessa Sangrenta", Erzsébet (Elizabeth) Bathory (1560-1614) foi uma nobre húngara que alegadamente matou mais de 650 jovens mulheres virgens. Sua monstruosidade foi construída a partir de fatos históricos e ficção, que a relacionam não apenas ao assassínio em série, mas também ao suposto lesbianismo, ao adultério e a acusações de vampirismo e feitiçaria.

${ }^{13}$ Antagonista do romance gótico de mesmo nome, de autoria do irlandês Joseph Sheridan Le Fanu. A história de Carmilla (1872) precede em 25 anos o Drácula de Bram Stoker.

${ }^{14}$ Vampiro protagonista de diversos romances da escritora Anne Rice (1941-), apresentado primeiramente aos leitores através do olhar de seu companheiro Louis em Entrevista com o vampiro (1976).

${ }^{15}$ Assassino em série dos romances de Thomas Harris (1940-) e de suas adaptações para o cinema. ${ }^{16}$ Psicopata que aparece pela primeira como protagonista do romance Psicose (1959), de Robert Bloch, interpretado por Anthony Perkins na adaptação para o cinema (Psicose, dir. Alfred Hitchcock, 1960).
} 
siedades. Os colaboradores da obra dedicam-se cuidadosamente aos monstros na cultura popular, não apenas do mundo anglófilo. Em suas profícuas análises, preocupam-se duplamente com a permanência e com a mudança - ou seja, com as formas pelas quais os monstros, antigos ou modernos, aparecem e reaparecem em diferentes contextos, nas mais diversas mídias. 